\title{
The influence of longwave ultraviolet radiation (u.v.-A) on the photosynthetic activity $\left({ }^{14} \mathrm{C}\right.$-assimilation) of plyytoplankton
}

\author{
B.Bühlmann, P.Bossard ${ }^{1}$ and U.Uehlinger \\ Institute of Aquatic Sciences (EAWAG), Swiss Federal Institute of \\ Technology (ETH). CH-8600 Dübendorf, Switzerland \\ ${ }^{\prime}$ To whom correspondence should be addressed at: Lake Research \\ Laboratory EAWAG/ETH, CH-6047 Kastanienbaum, Switzerland
}

\begin{abstract}
The impact of u.v. -A (315-400 nm) on phytoplanktonic C-assimilation has been studied in situ and in the laboratory under artificial light. Water samples from Lake Lucerne were placed in DURAN-glass bottles and incubated either covered or uncovered with u.v. absorbing transparent tubes, Exposure to u.v.-A clearly inhibited ${ }^{14} \mathrm{C}$-assimilation in the uncovered samples both in siu and in the laboratory. Variations in visible light intensity and filtering of $\mathrm{u} . v$.-B selectively demonstrated small inhibition of ${ }^{14} \mathrm{C}$-assimilation. U.v.-A inhibition of productivity is the major factor in the well known depression in productivity for surface waters.
\end{abstract}

\section{Introduction}

Phytoplankton incubated in bottles at different depths of a lake often show a marked decrease in ${ }^{14} \mathrm{C}$-assimilation close to the surface. This phenomenon is most apparent at noon, when light intensities are highest. Many authors have indicated that this decrease in photosynthetic rate is a light-induced effect (see literature review by Harris, 1978), and is therefore called 'photoinhibition'. There are, however, controversial issues on the causes of photoinhibition, especially as to the influences of light quality and u.v.radiation. Vollenweider and Nauwerck (1961) attribute photoinhibition to high intensities of the visible light spectrum, while Elster (1965), Jitts et al. (1976), and Jokiel and York (1984) stress the importance of u.v.-radiation. McLeod and McLachlan (1959) and Arnold (1933) showed that u.v.-radiation at a wavelength of $253.7 \mathrm{~nm}$ (u.v.-C) applied to algae before incubation with visible light, causes a reduction in photosynthesis. However, since u.v.-C does not reach the lake surface, its influence on photoinhibition is not of ecological importance. According to Findenegg (1966), Worrest et al. (1980), Hillman (1975), Halldal (1967) and Maske (1984), u.v.-B (280-315 nm) is capable of causing photoinhibition. Jokiel and York (1984) demonstrated growth inhibition primarily due to u.v.-B with some effect of u.v.-A (315-400 nm). Maske (1984) demonstrated carbon uptake inhibition primarily due to u.v.-A; conversely Bell and Merinova (1961), and Halldal (1967) attribute no photoinhibitory effect to u.v.-A.

U.v. and visible radiation affect $C$ assimilation at several levels. One level is the action spectra of the chlorophylls (Halldal, 1967; Bell and Merinova, 1961); another effect is at the level of physiological mechanisms (Harris, 1978), and finally there are environmental factors. This investigation was intended to evaluate the impacts of u.v.radiation and of visible light ( $\mathrm{PhAR}$ ) in natural environments on photoinhibition of phytoplankton primary production with special regard to the ${ }^{14} \mathrm{C}$-assimilation technique for the assessment of productivity depth profiles. 


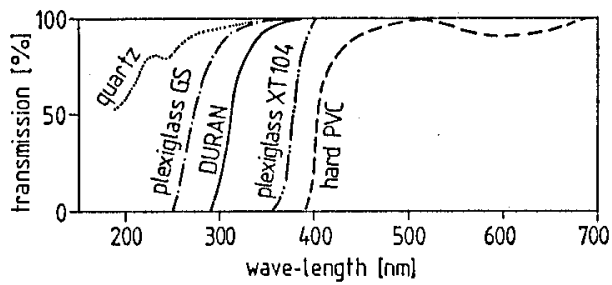

Fig. 1. Transmission characteristics of different materials measured in a spectrophotometer with a Deuterium lamp at wavelengths $<350 \mathrm{~nm}$, and with a Wolfram lamp $>350 \mathrm{~nm}$.

\section{Methods}

The relationship between photosynthesis $(\mathrm{P})$ and irradiance (I), the P/I-curve, was measured in phytoplankton using the ${ }^{14} \mathrm{C}$-assimilation technique on samples from Horw Bay, a basin of mesotrophic Lake Lucerne ( $430 \mathrm{~m}$ above sea level), taken from a depth of $2.5 \mathrm{~m}$, transferred into 100-ml DURAN or quartz bottles (for transmission characteristics, see Figure 1) and incubated for 4 h, from 10 a.m. to 2 p.m., either suspended at different depths in the lake or in light and temperature controlled laboratory incubators.

After incubation, the ${ }^{14} \mathrm{C}$-samples were processed by the acid bubbling method, according to Gächter and Màres (1978).

To investigate the impact of u.v.-A on ${ }^{14} \mathrm{C}$-assimilation, the DURAN bottles could be covered with transparent hard PVC tubes (for transmission characteristics see Figure 1). Photoinhibition (INH) in a non-covered bottle is defined as:

$$
\% \text { INH }=\frac{A_{\mathrm{cov}}(I)-A(I)}{A_{\mathrm{cov}}(I)} * 100
$$

where $A={ }^{14} \mathrm{C}$-assimilation in the uncovered bottle; $A_{\text {cov }}={ }^{14} \mathrm{C}$-assimilation in the covered bottle; $I=$ incident PhAR-intensity.

Laboratory incubations were carried out in incubators similar to those of Fee (1973). The front windows were transparent to u.v.-A and u.v.-B (see Figure 1, Plexiglas, GS-type, manufactured by Röhm GmbH, Darmstadt, FRG). High-pressure metal halide gas-discharge lamps (HPI $400 \mathrm{~W}$, made by Philips Company), and high-pressure mercury vapor fluorescent reflector lamps (HPL-R, $700 \mathrm{~W}$, made by Philips) furnished the photosynthetic active radiation (PhAR) through the front window, whereas tubular low-pressure mercury-vapor fluorescent lamps (TL 20 or $40 \mathrm{~W}$, colour $/ 09 \mathrm{~N}$, made by Philips) emitted u.v.-A (315-400 nm, emission maximum at $350 \mathrm{~nm}$, Figure 2) either from the front or from above. Since the HPL-R and HPI-lamps also emitted some u.v.-A radiation (Figure 2) u.v.-absorbing frontscreens (Plexiglas XT) were used if u.v.-A-radiation was not desired.

During incubations in the lake, PhAR was continuously monitored on the roof of the Lake Research Laboratory, $2 \mathrm{~km}$ from the sampling site, using a quantum sensor (LI 190) and a printing integrator (LI 550), both made by LI-COR Inc., Lincoln, NE, USA. The printing integrator yielded a continuous output of PhAR-integrals over intervals of $10 \mathrm{~min}$. The vertical distribution of PhAR in the lake water body was measured 

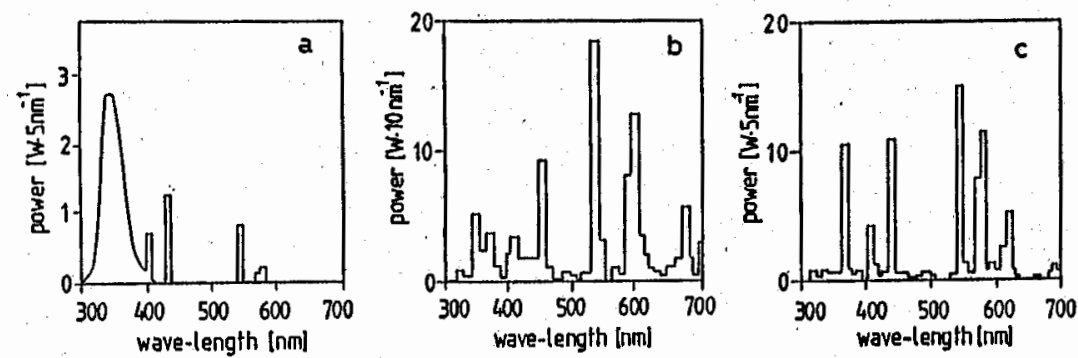

Fig. 2. Absolute spectral power distribution of artificial light sources (according to the specifications of

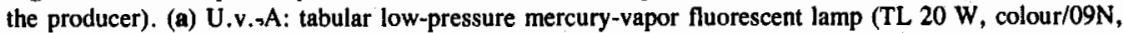
Philips); (b) high-pressure metal halide gas-discharge lamp (HPI $400 \mathrm{~W}$, Philips); (c) high-pressure mercury vapor fluorescent reflector lamp (HPL-R $700 \mathrm{~W}$, Philips).

with a scalar quantum sensor (LI $190 \mathrm{SB}$ ) and an integrating quantum meter (LI 188) made by LI-COR Inc. A second device served as a reference, measuring PhAR above the water surface. The same type of instrument was used for measurements above and below the water surface. U.v.-radiation was measured by a selenium photoelement, type GQ, made by Electrocell-Gesellschaft M.B.H., Falkenthal and Presser, Berlin, FRG. The window of the radiation spectrum was defined by filters of the type UG 1 (transmission 330-390 nm), made by Schott, Mainz, FRG. The sensors were calibrated with a $450 \mathrm{~W}$ Xenon lamp, a monochromator device, and a calibrated pyrometer at the Swiss Federal Institute of Technology (ETH) in Zürich (Institut für Festkörperphysik).

Total inorganic carbon was determined according to Rhode (1958). Chlorophyll $a$ was analyzed according to SCOR/UNESCO (1969).

\section{Results and Discussion}

\section{Influence of $u . v$. -radiation on in situ ${ }^{14} \mathrm{C}$-assimilation}

In June 1985 various incubations of Horw Bay samples, taken from $2.5 \mathrm{~m}$ depth, were carried out at different weather conditions. The DURAN bottles were incubated in a horizontal position pairwise in different depths between the surface and $10 \mathrm{~m}$ and therefore exposed to different light intensities. One bottle of each pair was covered with a transparent hard PVC tube which absorbs all u.v.-radiation $<390 \mathrm{~nm}$ wavelength and therefore prevents it from penetrating the sample. Figure 3 shows typical P/I-curves at different weather conditions from bright sunshine to completely overcast. The samples exposed to u.v.-radiation exhibited a marked decrease in C-assimilation at PhARintensities above $\sim 500 \mu \mathrm{Em}^{-2} \mathrm{~s}^{-1}$, while the samples excluded from exposure to u.v. did not show any inhibitory effect. From these and numerous similar results we conclude that solar radiation between 300 and $400 \mathrm{~nm}$ wavelength must cause photoinhibition. Since the DURAN glass bottles prevent the penetration of u.v.-radiation $<300 \mathrm{~nm}$, the effect must be limited mainly to u.v.-A. The results also demonstrate that photoinhibition is not limited to cloudless days; however, a minimum intensity of solar radiation is necessary to induce photoinhibition (Figure 3c). In Lake Lucerne, photoinhibition

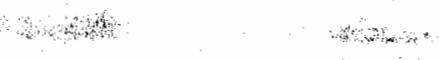



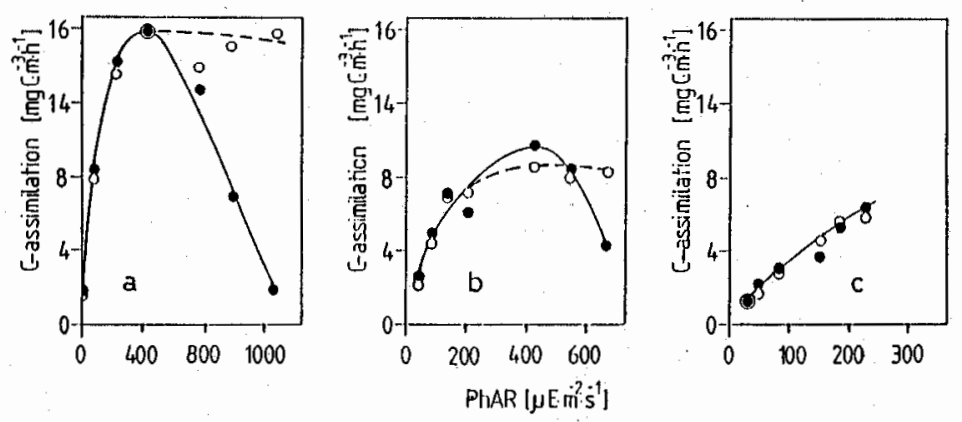

Fig. 3. ${ }^{14} \mathrm{C}$-Assimilation of phytoplankton (P/I curves): incubations in Horw Bay (Lake Lucerne) with and without the influence of u.v.-A. (a) Cloudless; (b) Cloudy; (c) overcast. - DURAN bottles, O_ODURAN bottles covered with hard p.v.c. Chlorophyll a concentration of sample $\mathrm{a}: 4.37 \mathrm{mg} \mathrm{m}^{-3}$, b: $3.97 \mathrm{mg} \mathrm{m}^{-3}$, c: $2.52 \mathrm{mg} \mathrm{m}^{-3}$.
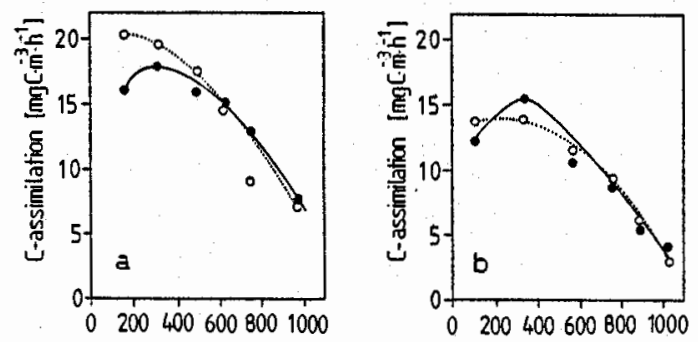

PhAR $\left[\mu E \cdot \dot{m}^{2} \cdot s^{-1}\right]$

Fig. 4. Comparison between ${ }^{14} \mathrm{C}$-assimilation rates measured in $-\bullet$ DURAN and in $\mathrm{O} \ldots \ldots$ quartz bottles incubated in Horw Bay. Chlorophyll $a$ concentration of sample a: $5.66 \mathrm{mg} \mathrm{m}^{-3}, \mathrm{~b}: 4.33 \mathrm{mg}$ $\mathrm{m}^{-3}$.

has been observed as deep as $2-3 \mathrm{~m}$ from the surface, and may therefore affect a substantial part of the photosynthetically active phytoplankton.

To determine the contribution of U.v.-A and u.v.-B to photoinhibition, similar in situ experiments with quartz and DURAN bottles were performed. At higher light intensities, the two bottle types yield approximately the same assimilation rates (Figure 4). At lower light intensities, however, quartz may permit slightly higher C-assimilation. This result corresponds to the observations of Findenegg (1966), Worrest et al. (1980), Hillman (1975), Ilmavirta and Hakala (1972). Experiments in marine environments from Lorenzen (1979) on a sunny day in August at latitudes comparable to central Europe demonstrated that exclusion of U.v.-B would increase carbon uptake near the surface by 1.1-2 times. The authors concluded however, that the effect of U.v.-B on present day estimates of oceanic production is minimal. A relatively insignificant role of u.v.$B$ is to be expected in view of the small amounts of $u . v .-B$ reaching the lake surface (Bener, 1963) and of the high absorption capacity of water for u.v.-B (Tyler and Smith, 1970; Baker and Smith, 1982). Therefore, our experiments support the conclusion that naturally occurring u.y.-B does not enhance photoinhibition significantly when superimposed to the naturally occurring u.v.-A effect. 
Table I. Vertical profiles for u.v.-A- and PhAR-irradiances in Horw Bay (in $\mu \mathrm{Em}^{-2} \mathrm{~s}^{-1}$ ), and for u.v.-A in \% of PhAR of the same depth.

\begin{tabular}{|c|c|c|c|c|c|c|}
\hline \multirow[t]{2}{*}{$\begin{array}{l}\text { Depth } \\
\text { (m) }\end{array}$} & \multicolumn{3}{|c|}{$\begin{array}{l}\text { June } 6,1985 \text {; cloudless day at } \\
\text { approximately } 2 \text { p.m. }\end{array}$} & \multicolumn{3}{|c|}{$\begin{array}{l}\text { June } 22,1985 \text {; completely cloudy day at } \\
\text { approximately } 9 \text { a.m. }\end{array}$} \\
\hline & $\begin{array}{l}\mathrm{PhAR} \\
\left(\mu \mathrm{Em}^{-2} \mathrm{~s}^{-1}\right)\end{array}$ & $\begin{array}{l}\mathrm{U} \cdot \mathrm{v} \cdot-\mathrm{A} \\
\left(\mu \mathrm{Em}^{-2} \mathrm{~s}^{-1}\right)\end{array}$ & $\begin{array}{l}\text { U.v.-A (\% } \\
\text { of PhAR }\end{array}$ & $\begin{array}{l}\text { PhAR } \\
\left(\mu \mathrm{Em}^{-2} \cdot \mathrm{s}^{-1}\right)\end{array}$ & $\begin{array}{l}\text { U.v. }-\mathrm{A} \\
\left(\mu \mathrm{Em}^{-2} \mathrm{~s}^{-1}\right)\end{array}$ & $\begin{array}{l}\text { U.v.-A (\% } \\
\text { of PhAR) }\end{array}$ \\
\hline Surface & 2123 & 200 & 9.4 & 401 & $30.6^{\circ}$ & 7.6 \\
\hline 0.5 & 1686 & 124 & 7.4 & 298 & 13.6 & 4.6 \\
\hline 1 & 1397 & 63 & 4.5 & 238 & 5.7 & 2.4 \\
\hline 2 & 932 & 27 & 2.9 & 163 & 1.2 & 0.7 \\
\hline 3 & 712 & 8 & 1.1 & 110 & 0.4 & 0.4 \\
\hline 4 & 458 & 3.4 & 0.7 & 65 & 0.2 & 0.3 \\
\hline 5 & 325 & 2.5 & 0.8 & 50 & 0.1 & 0.2 \\
\hline
\end{tabular}

\section{U. $v .-A$ radiation in situ}

Table I shows a typical vertical profile for u.v.-A (filter UG1: $330-390 \mathrm{~nm}$ ) and PhAR $(400-700 \mathrm{~nm}$ ) in Horw Bay measured (i) on a cloudless day at approximately 2 p.m. and (ii) on a completely cloudy day at approximately 9 a.m. only 8 days apart from each other. The results show that the u.v.-A radiation at the water surface varies substantially from $\sim 200-31 \mu \mathrm{Em}^{-2} \mathrm{~s}^{-1}$ with corresponding intensities of $63-5.7 \mu \mathrm{Em}^{-2}$ $\mathrm{s}^{-1}$ at a depth of $1 \mathrm{~m}$ for (i) and (ii) respectively. Even at low light intensities, there is significant u.v.-A radiation up to a depth of $1 \mathrm{~m}$. Therefore, the u.v.-A radiation cannot be neglected in the uppermost layers of natural surface waters (see also Findenegg, 1966). For u.v.-A, the $10 \%$ level (of the surface radiation) is located at a depth of $\sim 2 \mathrm{~m}$, while for PhAR the $10 \%$ level is below $5 \mathrm{~m}$, confirming that u.v. $-\mathrm{A}$ is absorbed in the water body more efficiently than PhAR. At equal PhAR-intensities ${ }^{14} \mathrm{C}$ assimilation is therefore inhibited to a greater extent closer to the surface.

Monitoring diurnal courses of PhAR and u.v.-A in summer and autumn demonstrated, that with increasing sun altitude, the u.v.-A-intensity becomes relatively larger in comparison to the PhAR-intensity, due to the fact that in the atmosphere short wavelengths are absorbed more efficiently, obviously independent on the weather conditions (see Figure 5).

\section{Influence of u.v.-A- and PhAR-radiation on ${ }^{14} \mathrm{C}$-assimilation}

These experiments served to estimate the influence of u.v.-A $(315-400 \mathrm{~nm})$ at different radiation intensities in combination with different PhAR-intensities under controlled laboratory conditions. All experiments were carried out with Horw-Bay water from $2.5 \mathrm{~m}$ depth between August 8 and October 15, 1985. The samples were incubated in parallel, one bottle as such and one covered with u.v.-absorbing transparent hard p.v.c.

Different experiments using different light sources were set up:

HPL-R or HPI from the front and u.v.-A from the top yielded a PhAR gradient from front to rear of the incubator at constant u.v.-A intensities for all samples.

HPL-R or HPI and u.v.-A from the front yielded both PhAR and u.v.-A gradients from front to rear of the incubator.

Preliminary experiments (Bossard, unpublished) showed, that different compositions in the visible light spectrum from $400-700 \mathrm{~nm}$ (PhAR) of the natural and artificial 


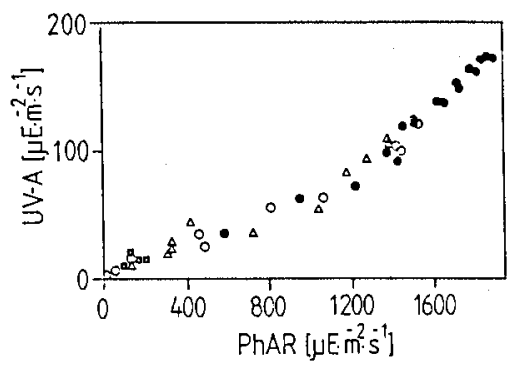

Fig. 5. Ratio of incident PhAR- and u.v.-A radiation above the water surface ( $430 \mathrm{~m}$ above sea level) at different weather conditions, - cloudless, $O$ cloudy, $\square$ overcast, $\triangle$ fog.

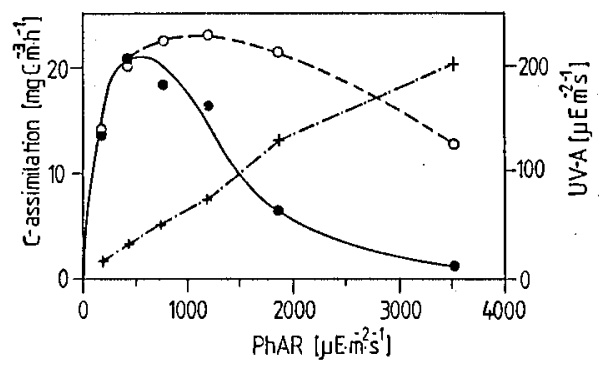

Fig. 6. The influence of u.v.-A radiation on ${ }^{14} \mathrm{C}$-assimilation (P/I-curves) of Horw Bay phytoplankton from $2.5 \mathrm{~m}$ depth incubated at artificial light (HPI): - - DURAN bottles; $0 . .$. O DURAN bottles covered with transparent hard PVC; +- - - - + u.v.-A radiation. Chlorophyll $a$ concentration of sample: $5.10 \mathrm{mg} \mathrm{m}^{-3}$.

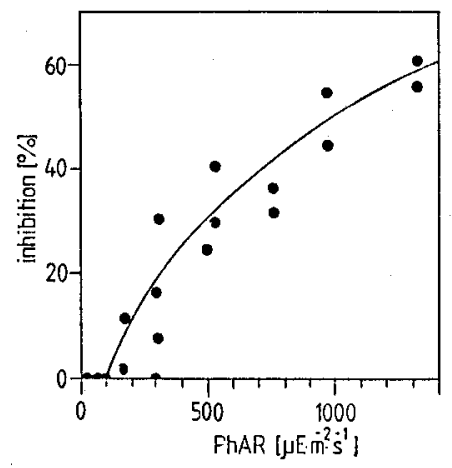

Fig. 7. Relation between photoinhibition and PhAR-intensity at a mean u.v.-A intensity of $85.8 \pm$ $2.0 \mu \mathrm{Em}^{-2} \mathrm{~s}^{-1}$. Experimental set up: see Figure 8 .

light sources (sunlight, HPL-R, HPI, Tungsten halogen vapor lamp) did not lead to different ${ }^{14} \mathrm{C}$-assimilations at equal PhAR-intensities. Moreover, no 'slow light adaption process' changing ${ }^{14} \mathrm{C}$-assimilation rates within the first $6 \mathrm{~h}$ of incubation has been observed (Bossard unpublished). That means that at constant radiation intensities $\mathrm{P} / \mathrm{I}$ 

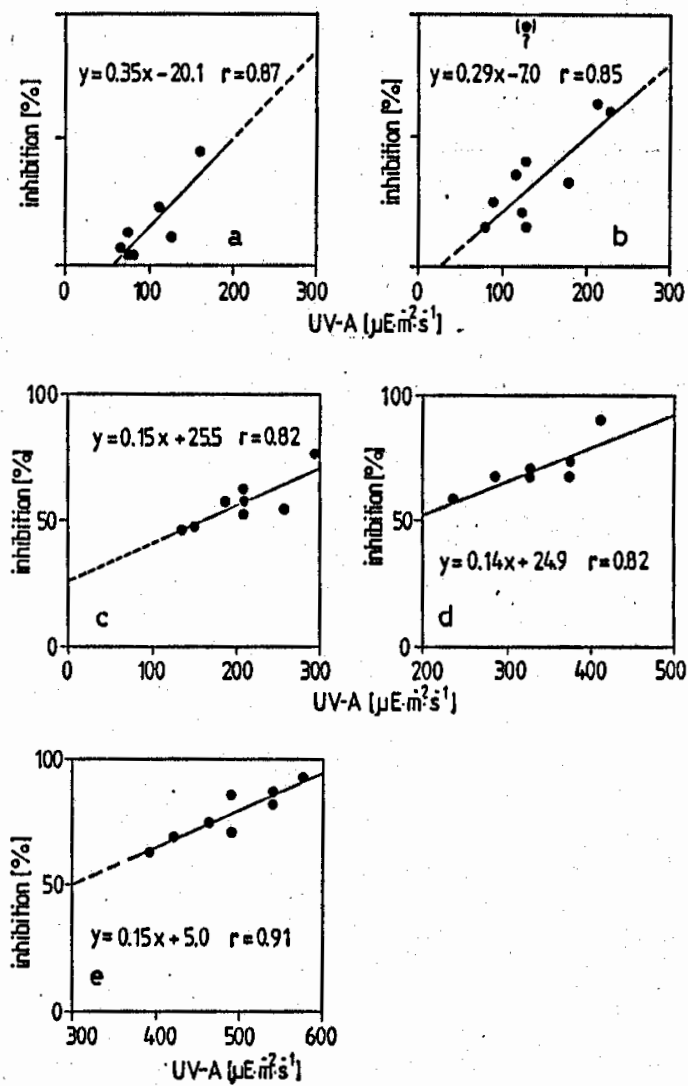

Fig. 8. Relation between photoinhibition and u.v.-A at constant PhAR-intensities. Summary of ${ }^{14} \mathrm{C}$ assimilation measurements with Horw Bay phytoplankton incubated in the presence of U.v.-A and an HPL-R light source. PhAR-intensities: (a) $300 \mu \mathrm{Em}^{-2} \mathrm{~s}^{-1}$, (b) $500 \mu \mathrm{Em}^{-2} \mathrm{~s}^{-1}$, (c) $790 \mu \mathrm{Em}^{-2} \mathrm{~s}^{-1}$, (d) $1100 \mu \mathrm{Em}^{-2} \mathrm{~s}^{-1}$, (e) $1480 \mu \mathrm{Em}^{-2} \mathrm{~s}^{-1}$.

curves did not shift with time during the $4 \mathrm{~h}$ standard incubation period.

Figure 6 shows a typical P/I curve obtained from an experiment with the HPI-lamp which yields high light intensities up to $\sim 3500 \mu \mathrm{Em}^{-2} \mathrm{~s}^{-1}$ just behind the front window. The right hand scale indicates the corresponding u.v.-A intensities for the noncovered bottles. The difference in assimilation between covered and non covered bottles at PhAR intensities $>500 \mu \mathrm{Em}^{-2} \mathrm{~s}^{-1}$ is obvious: while C-assimilation in u.v.-A filtered bottles demonstrates minimal inhibition below PhAR intensities of $\sim 1800 \mu \mathrm{Em}^{-2} \mathrm{~s}^{-1} \mathrm{C}$-assimilation in unfiltered bottles shows considerable inhibition. Even at an extremely high PhAR intensity of $3500 \mu \mathrm{Em}^{-2} \mathrm{~s}^{-1}$, the observed photoinhibition, caused by visible light only, is $<50 \%$. However, PhAR-intensity dependent photoinhibition is significantly enhanced in the presence of u.y.-A (see Figure 7).

The effect of varying u.v.-A intensities on photosynthesis at constant PhAR intensities is shown in Figure 8a-e. The slopes of the regression lines (photoinhibition as 
a linear function of u.v.-A) indicate that at lower light intensities photosynthesis seems to react more sensitively to changes in $u . v .-A$ intensity. Additional experiments have shown that combinations of U.v.-A and PhAR-radiation between 0 and $70 \mu \mathrm{Em}^{-2} \mathrm{~s}^{-1}$ for u.v.-A and between 0 and $300 \mu \mathrm{Em}^{-2} \mathrm{~s}^{-1}$ for PhAR did not cause inhibition in C-assimilation.

The results of the laboratory experiments can be summarized as follows: (i) Without u.v.-A, there is no photoinhibition whatsoever at PhAR-intensities between 0 and $1800 \mu \mathrm{Em}^{-2} \cdot \mathrm{s}^{-1}$. (ii) At PhAR-intensities $<300 \mu \mathrm{Em}^{-2} \mathrm{~s}^{-1}$ there is a threshold level of $70 \mu \mathrm{Em}^{-2} \mathrm{~s}^{-1}$ u.v.-A, below which no photoinhibition occurs (at PhAR-intensities $>300 \mu \mathrm{Em}^{-2} \mathrm{~s}^{-1}$ we lack experimental data to establish a threshold level for u.v.A). (iii) At PhAR-intensities $>300 \mu \mathrm{Em}^{-2} \mathrm{~s}^{-1}$ and u.v.-A-intensities above $>70 \mu \mathrm{Em}^{-2} \mathrm{~s}^{-1}$, photoinhibition is always observed to a certain degree depending on the combination of PhAR- and u.v.-A-intensities (Figure 8). (iv) There is a curvilinear relationship between the degree of photoinhibition and PhAR-intensity at a constant u.v.-A intensity (Figure 7). (v) At PhAR-intensities from $\sim 200-1500 \mu \mathrm{Em}^{-2} \mathrm{~s}^{-1}$, there is a linear or curvilinear relationship between the degree of photoinhibition and u.v.-A-intensity at constant PhAR intensities (Figure 8).

\section{Summary and conclusions}

This study was intended to treat some empirical aspects of photoinhibition observed in situ, and to establish some semiquantitative relationships between PhAR, u.v.-A and photoinhibition, which may be of practical use for the calculation of primary production in lakes. The assessment of more accurate quantitative relationships on a physiological base, however, has yet to be carried out.

For primary production measurements the following knowledge is of practical use. The well-known feature of near surface depression observed in productivity depth profiles in moderate latitudes is caused by $u . v$.-A radiation (i.e. $315-400 \mathrm{~nm}$ ). The additional influence of U.v.-B is of minor importance to photoinhibition. High intensities of visible light ( $\mathrm{PhAR}$ ), up to $1800 \mu \mathrm{Em}^{-2} \mathrm{~s}^{-1}$ ) occurring naturally in moderate latitudes cause only minor photoinhibitions in the absence of u.v.-A.

The use of DURAN (Pyrex) incubation bottles for the assessment of in situ Cassimilation is reasonable in view of the influence of u.v.-radiation, since artifacts caused by absorption characteristics of the glass wall hardly bias the measurements when compared to quartz. However, other glass qualities or even plexiglass, p.v.c. and plastic materials have to be checked carefully before they are used for photosynthesis experiments. The same precautions are needed for experiments with laboratory incubators: the quality of the light source (especially the u.v.-spectrum) and the absorption characteristics of the window or screen between the light source and the incubated bottles have to be known precisely, if any conclusions on photoinhibition should be drawn from such experiments. If in situ conditions are to be simulated in laboratory incubators, u.v.-A radiation sources in addition to sources of visible light are indispensable and all screens and windows between the radiation source and the incubated bottles have to be transparent to u.v.-A.

Since the true intensity of u.v.-A reaching a certain depth below the water surface cannot be calculated prectsely from measurement of PhAR alone, it is recommended 
to monitor U.v.-A radiation at the surface and to measure u.v.-A depth profiles on the day of primary production measurements, if photoinhibition is to be modelled. For the same reason, primary production models may not always be satisfactory, if photoinhibition is assumed to be a sole function of PhAR-intensity.

\section{Acknowledgements}

We are indebted to B.Germann for expert technical assistance and to B.Falsom, J.Bloesch and R.Gächter for.comments and criticism.

\section{References}

Arnold,W. (1933) The order of the blackman reaction in photosynthesis. J. Gen. Physiol, 17, 145-149. Baker,K.S. and Smith,R.C. (1982) Spectral irradiance penetration in natural waters. In Calkins,J. (ed.), The Role of Solar Ultraviolet Radiation in Marine Ecosystems. Plenum Press, New York, pp. 233-246.

Bell,L.N. and Merinova,G.L. (1961) Effect of dose and wavelength of ultra-violet radiation on photosynthesis of chlorella. Biofizika, 6, 159-164.

Bener,P. (1970) Measured and Theoretical Values of the Spectral Imtensity of Ultraviolet Zenith Radiation and Direct Solar Radiation at 316, 1580 and 2818 m.a.s.l. AFCRL, Contract F 61052-67-C-0029, July.

Elster,H.J. (1965) Absolute and relative assimilation rates in relation to phytoplankton populations. Mem. Ist. Ital. Idrobiol., 18 Suppl., 77-103.

Fee,E.J. (1973) A numerical model for determining integral primary production and it's application to Lake Michigan. J. Fish. Res. Bd. Canada, 30, 1447-1468.

Findenegg,I. (1966) Die Bedeutung kurzwelliger Strahlung für die planktische Primärproduktion in den Seen. Verh., Int. Ver. Theor. Anigew. Limnol., 16, 314-320.

Gächter,R. and Mares,A. (1979) Comments on the acidification and bubbling methods for determining phytoplankton production. Oikos, 33, 69--73.

Halldal,P. (1967) Ultraviolet action spectra in algology. A review. Photochem. Photobiol, , 6, 445-460.

Harris,G.P. (1978) Photosynthesis, productivity and growth: the physiological ecology of phytoplankton. Arch. Hydrobiol. Beih. Ergebn. Limnol., 10, 1-171.

Hillman,T.J. (1975) Comparison of materials for enclosure of samples during carbon-14 measurements of phytoplankton productivity. Bull. Aust. Soc. Limnol., 6, $1-4$.

Ilmavirta,V. and Hakala, 1. (1972) Acrylic plastic and Jena glass bottles used in measuring phytoplanktonic primary production by the ${ }^{14} \mathrm{C}$ method. Ann. Bot. Fennici, 9, 77-84.

Jitts,H.R., Morel,A. and Saijo,Y. (1976) The relation of oceanic primary production to available photosynthetic irradiance. Aust. J. Mar. Freshwater Res., 27, 441-454.

Jokiel,P.L. and York,R.H. (1984) Importance of ultraviolet radiation in photoinhibition of microalgal growth. Limnol. Oceanogr., 29, 192-199.

Lorenzen,C.J. (1979), Ultraviolet radiation and phytoplankton photosynthesis (3). Limnol. Oceanogr., 24, $1117-1120$.

Maske,H. (1984) Daylight ultraviolet radiation and the photoinhibition of phytoplankton carbon uptake. $J$. Plankton Res., 6, $351-357$.

McLeod,G.C. and McLachlan,J. (1959) The sensitivity of several algae to ultraviolet radiation of $2537 \AA$. Physiol. Plant., 12, 306-309.

Rodhe,W. (1958) The primary production in lakes: some results and restrictions of the ${ }^{14} \mathrm{C}$ methods. Rapp. Proc,-verb. J. Cons. Perm. Int. Expl. Mer., 144, 122-128.

SCOR/UNESCO (1969) Determination of photosynthetic pigments in sea-water. Monographs on Oceanographic Methodology: UNESCO, Paris, 1, 16-17.

Tyler,J.E, and Smith,R.C. (1970) Measurement of Spectral Irradiance Underwater. Gordon and Breach, New York.

Vollenweider,R.A. and Nauwerck,A. (1961) Some observations on the C14 method for measuring primary production. Verh., Int. Ver. Theor. Angew. Limnol., 14, 134-139.

Worrest,R.C., Brooker,D.L. and Van Dyke,H. (1980) Results of a primary productivity study as affected by the type of glass in the culture bottles. Limnol. Oceanogr., 25, 360-364.

Received on September 8, 1986; accepted on May 20, 1987 